\title{
Decreased Incidence of Clotted AV Access in Hemodialysis Patients after the Implementation of Follow up Program
}

\author{
Awad Magbri ${ }^{1}$, Patricia McCartney ${ }^{1}$, Eussera El-Magbri ${ }^{2}$, Mariam El-Magbri ${ }^{3}$ \& Taha El-Magbri ${ }^{4}$ \\ ${ }^{1}$ Dialysis Access Center of Pittsburgh, PA, USA \\ ${ }^{2}$ George Washington School of Medicine, DC, USA \\ ${ }^{3}$ American University, Washington DC, USA \\ ${ }^{4}$ University of Pennsylvania, Philadelphia, USA \\ Correspondence: Awad Magbri, Dialysis Access Center of Pittsburgh, PA, USA. E-mail: elmagbri@hotmail.com
}

Received: December 24, 2015 Accepted: January 14, $2016 \quad$ Online Published: February 24, 2016

doi:10.5539/gjhs.v8n10p81

URL: http://dx.doi.org/10.5539/gjhs.v8n10p81

\begin{abstract}
Background and Objectives: Access monitoring and pre-emptive angioplasty is known to decrease the incidence of AVF/AVG thrombosis. The effect on increase the longevity and functionality of Arterial-Venous access (AV access) in end-stage renal disease (ESRD) patients is not settled. Thrombosis is the leading cause of vascular access complications and is almost always associated with the presence of stenosis. Percutaneous transluminal angioplasty (PTA) is an accepted treatment of stenotic lesions in AV access (NKF 2001). The purpose of this study is to assess the effect of follow up of ESRD patients in the dialysis access center with preemptive angioplasty on access thrombosis.
\end{abstract}

Design, Setting, Participants, \& Measurements: This is a single center observational interventional study extended over 9 years (Jan 1, 2006 to Dec 31, 2014) at the Dialysis Access Center of Pittsburgh, PA. The study is divided into 2 periods, period A (from Jan 2006 to December 2009), where follow up program was not in place. Period B extends from (January 1, 2011 to December 31, 2014). In this period, a follow up of patients with preemptive angioplasty of AV access has been implemented. We decided not to include 2010 as the program is implemented at the end of that year and including this year might skewed the data. All patients with ESRD on HD are seen in the Dialysis access center of Pittsburgh for access monitoring and interventional PTA if deemed necessary. Patients' data were abstracted from the electronic medical records. The study is approved by the IRB of Lifeline corp.

Results: During period A; a total of 4139 encounters with a mean of 1034, (1653 angioplasties with mean of 413/year, 375 angiogram, mean 94/year, and 303 thrombectomies of AVF/AVG with a mean 76/year) were carried out. Thrombectomies constituted $(7.3 \%)$ of the total procedures performed.

Table 1 showed the mean distributions of AVG, AVF, and tunneled dialysis catheters (TDC) frequencies compared to national average in periods A \& $\mathrm{B}$.

In period B, a total of 6229 encounters with mean of 1557 encounter/year were performed, (3202 angioplasties, mean 801/year, 950 angiograms, mean 238/year, and 196 thrombectomies, mean 42/year) were done. Thrombectomies were decreased almost 2 folds in this period $(7.3 \%$ to $3.15 \%)$.

The percentage of patients being dialyzed via TDC decreased in period B from $31.895 \%$ to $17.38 \%$. The numbers of thrombectomies have also been decreased from average 76 to 42 /year (7.3\% to $3.15 \%)$.

After implementing the program, as illustrated in period B, compared to the national average, the frequency of thrombectomies (3.15\% vs. 9.6\%) and TDC use $(17.38 \%$ vs. $18 \%$ ), have showed significant improvement. Meanwhile, the number of PTA has doubled from an average of (413 to 801/year) between the 2 periods. Our fistula rate has gone up from $48.7 \%$ to $66.2 \%$ between the 2 periods. Mild increase of the AVG use $(12.07 \%$ to $18.07 \%)$ has also been observed. However, the use of TDC has decreased from (31.42\% to $17.38 \%)$. These results are consistent with the motto of (fistula first and catheter last). The growth of PTA may explain the positive impact of this program on the number of thrombectomies as well as maintenance of access functionality in ESRD patients. The rate of PTA has gone up from (39.85\% to 51.25\%). This trade off may be acceptable if 
access patency and functionality have to be maintained. It is not clear whether the follow up program with preemptive angioplasty would have a positive effect on the access expenditure and access longevity in this group of patients.

Conclusion: Follow up of ESRD patients in the dialysis access center and preemptive angioplasty if need be is an acceptable means to decrease the number of failed accesses, thrombectomies, as well as the use of TDC in ESRD patients.

Keywords: pre-emptive angioplasty, Arterial-Venous access, end-stage renal disease, thrombectomies

\section{Introduction}

There has been tremendous growth of end-stage renal disease (ESRD) in the United States with more than 600,000 patients in 2011 with around 400,000 patients on dialysis (USRDS, 2013). Patients with ESRD consume disproportionate health care resources, despite making up only $1.3 \%$ of the Medicare population. They accounted for $6.2 \%$ of the Medicare expenditures in 2011, (USRDS, 2013; Gorodetskaya, 2005; US census Bureau, 2012). Vascular access share accounts for approximately 10\% of the total ESRD program costs (Feldman, 1996; Manns, 2005).

Access monitoring and pre-emptive angioplasty is known to decrease the incidence of AVF/AVG thrombosis (Schwab, 1995; Besarab, 1995; Safa, 1992; Smits, 2001). The results on increasing the longevity and functionality of Arterial-Venous access (AV access) in ESRD patients are still not settled. Different studies have demonstrated reduced thrombosis (Ram, 2003; Allon, 2007; Whittier, 2011) and perhaps prolongation of the cumulative patency of AV fistula and grafts (Tessitor, 2008), while others fail to yield significant effects (Moist, 2003; Dember, 2004). Thrombosis is the leading cause of vascular access complications and is almost always associated with the presence of stenosis. Percutaneous transluminal angioplasty (PTA) is an accepted treatment of stenotic lesions in AV access (NKF, 2001). The purpose of this study is to assess the effect of follow up of ESRD patients in the dialysis access center with preemptive angioplasty on access thrombosis.

\section{Material and Methods}

\subsection{Participants and Study Design}

We analyzed the effect of follow up program on the number of thrombectomies and angioplasties on a cohort of adults hemodialysis patients who had fistula or graft between January 1, 2006 and December 31, 2014 at the Dialysis Access Center of Pittsburgh, PA. A total of 6082 patients with 10368 encounters were included in the study. The age range is 23 to 92 years with mean age of 64 years. There were $50.92 \%$ males and $57.25 \%$ diabetics. Patients' data were abstracted from the electronic records of Lifeline data base.

This is a single center observational interventional study extended over 9 years at the Dialysis Access Center of Pittsburgh, PA. The study is divided into 2 periods, period A (from January 1, 2006 to December 31, 2009) where follow up program was not in place. Period B is from (January 1, 2011 to December 31, 2014) where a follow up of patients with preemptive angioplasty of AV access has been implemented. We decided not to include 2010 as the program is implemented at the end of that year and including this year might skewed the data. All patients with ESRD on HD are seen in the Dialysis access center of Pittsburgh for access monitoring and interventional PTA if deemed necessary. The study is approved by the IRB of Lifeline corp.

The follow up program entails the following:

- The patients are brought to the dialysis access center for clinical examination and/or ultrasound evaluation of their access. The treating interventionalists is reviewing the clinical and dialysis data of the patients and incorporates the results of the US and clinical examinations of the access and forms an educated decision. This information decides whether to take the patient to the procedure room for angiogram of the access and/or angioplasty.

- For patients who had thrombectomy or angioplasty performed- post-operative visit scheduled;

o Thrombectomy in 1 month.

- Central vein angioplasty in 2 months.

$\circ$ Regular angioplasty in 3 months.

Notes on subsequent post operative visit- Assumptions made in modeling protocol:

- Central vein angioplasty patients who have a post op angioplasty performed continue to be scheduled 2 months out for subsequent post op visit. 
- Thrombectomy patients who have a post op angioplasty performed are subsequently scheduled one month and then 3 months out for a post op visit (similar to regular angioplasty patient).

- Any patients that have a good flow and normal angiogram will be scheduled for a clinical examination in 6 months.

- In the following visit if medically necessary angiogram is performed and angioplasty is done then the patient is scheduled for upcoming visit to the DAC which depends on the following;

○ Nature of the lesion

o Site of the lesion

$\circ$ Natural history of the lesion and the time interval of recurrence of the symptoms and signs relevant to the access.

o The interval between visits can be increased or decreased depending on the above factors.

The decision to take the patient to the operating room is entirely lift to the discretion of the treating interventionalist. The treating interventionalist incorporates all data from clinical examination of the access, the ultra-sound evaluation, and the clinical and dialysis data from the Vasc-alert, flow studies, clearance and pressure studies of the monitoring modality used by the dialysis unit before forming an educated decision.

\subsection{Measures and Definitions}

All procedures of angioplasties, angiograms, thrombectomies, catheter exchanges and catheter placements that were done at the Access center of Pittsburgh from January1, 2006 to December 31, 2014 were compared in the 2 periods (A and B). Physical examination of the AV access along with ultra-sound evaluation was carried out at the Access by the interventionalists. Thrombectomy, angioplasty or angiogram were done at the discretion of the interventionalists. Thrombosis of the access is diagnosed if there was no flow in the access and or the presence of intra-vascular clot on ultra-sound evaluation. Successful thrombectomy is defined as one dialysis session via the access following the procedure. Angioplasty is successful if the residual after angioplasty is $<30 \%$.

\section{Results}

There were 10,368 encounters during the entire follow up study. The total numbers of cohort patients with ESRD included in the study, from (January 1, 2006 to December 31, 2014), are 6082 patients. The demographic data are shown in Table 1.

Table 1. Demographic data of ESRD patient

\begin{tabular}{ll}
\hline Total encounters & 10,368 \\
\hline Number of Patients & 6082 \\
\hline Age range, & 23 to 92 years \\
Mean & 64 years \\
\hline Diabetes & $57.25 \%$ \\
\hline Male: female & $50.92: 49.08$ \\
\hline Percentage of access type & \\
AVF & $66.15 \%$ \\
AVG & $13.09 \%$ \\
TDC & $24.64 \%$ \\
\hline
\end{tabular}

During the follow up period, the incident rate of AVF and to a lesser extent the AVG have been increased compared to the national average, Table 2. 
Table 2. Percentage of AVF, AVG, and TDC compared to the national average.

\begin{tabular}{lllllllll}
\hline \multicolumn{3}{c}{ Pre-follow up program } & \multicolumn{5}{c}{ Post-follow up program } \\
\hline $\begin{array}{l}\text { Access } \\
\text { type }\end{array}$ & 2006 & 2007 & 2008 & 2009 & 2011 & 2012 & 2013 & 2014 \\
\hline AVF & $46.82(32.92)$ & $47.62(35)$ & $47.35(35.23)$ & $50.85(36.61)$ & $63.55(41.78)$ & $68.25(44.08)$ & $70.85(44.91)$ & $70.30(44.57)$ \\
AVG & $12.85(37.05)$ & $13.01(27.97)$ & $10.53(25.87)$ & $11.87(25.17)$ & $13.72(25.01)$ & $14.83(23.59)$ & $13.80(21.52)$ & $14.07(21.55)$ \\
TDC & $32.57(26.40)$ & $31.67(31)$ & $33.82(32.25)$ & $29.52(30.74)$ & $22.20(24.96)$ & $16.75(22.54)$ & $15.20(21.08)$ & $15.38(19.90)$ \\
\hline
\end{tabular}

AVF-arterial-venous fistula, AVG- arterial-venous graft, TDC- tunneled dialysis catheter;

Numbers represent the percentage, the number between the prentices are the national average.

The reasons for referral to the Access center of Pittsburgh are shown in Table 3. The reason for inadequate blood flow as a referral has decreased from $18.69 \%$ to $7.32 \%$ in period B. The incident rate of clotted access decreased from $7.3 \%$ in period A to $3.15 \%$ after follow up program implementation. The incident of bleeding has gone up in period B to $11.32 \%$ from $5.43 \%$. The reason for this increase is not entirely clear. The percentage of follow up visits has also gone up to $23.15 \%$ from $1.47 \%$.

Table 3. Reason for referral to the access center

\begin{tabular}{|c|c|c|c|c|c|c|c|c|}
\hline \multicolumn{5}{|l|}{ Pre-follow up program } & \multicolumn{4}{|c|}{ Post-follow up program } \\
\hline Reason for referral & 2006 & 2007 & 2008 & 2009 & 2011 & 2012 & 2013 & 2014 \\
\hline $\begin{array}{l}\text { Inadequate blood flow to the } \\
\text { dialysis machine }\end{array}$ & $24.43 \%$ & $10.52 \%$ & $9.33 \%$ & $10.48 \%$ & $9.54 \%$ & $7.76 \%$ & $4.65 \%$ & \\
\hline Malfunction catheter & $13.23 \%$ & $10.75 \%$ & $7.62 \%$ & $3.97 \%$ & $4.83 \%$ & $3.45 \%$ & $2.22 \%$ & $1.55 \%$ \\
\hline Clotted access & $10.31 \%$ & $8.60 \%$ & $7.45 \%$ & $8.79 \%$ & $3.61 \%$ & $3.43 \%$ & $1.67 \%$ & $1.67 \%$ \\
\hline $\begin{array}{l}\text { Determination of access } \\
\text { placement }\end{array}$ & $9.8 \%$ & $8.48 \%$ & $10.10 \%$ & $8.74 \%$ & & & & \\
\hline $\begin{array}{l}\text { Mature access/catheter } \\
\text { removal }\end{array}$ & $5.73 \%$ & $7.92 \%$ & $6.68 \%$ & $8.67 \%$ & $8.46 \%$ & $7.08 \%$ & $4.44 \%$ & $4.46 \%$ \\
\hline $\begin{array}{l}\text { Increase venous or arterial } \\
\text { pressure }\end{array}$ & $5.22 \%$ & $7.01 \%$ & $6.08 \%$ & $5.65 \%$ & $3.47 \%$ & $6.01 \%$ & $6.91 \%$ & $5.08 \%$ \\
\hline Unable to cannulate & $4.96 \%$ & $5.88 \%$ & $5.82 \%$ & $4.60 \%$ & $4.80 \%$ & $5.21 \%$ & $3.45 \%$ & $3.41 \%$ \\
\hline bleeding & $3.44 \%$ & $4.64 \%$ & $6.42 \%$ & $7.21 \%$ & $11.40 \%$ & $13.36 \%$ & $12.08 \%$ & $8.43 \%$ \\
\hline Swollen extremity & $2.67 \%$ & $4.07 \%$ & $3.60 \%$ & $2.93 \%$ & $3.47 \%$ & $2.95 \%$ & $2.31 \%$ & $1.80 \%$ \\
\hline Follow up & $1.53 \%$ & $1.36 \%$ & $0.60 \%$ & $2.39 \%$ & $25.65 \%$ & $27.04 \%$ & $21.48 \%$ & $18.41 \%$ \\
\hline
\end{tabular}

Thrombectomy number has decreased dramatically in period B. Table 4 . The numbers of angioplasty in the same period have increased, (51.25\% from 39.86\%). as shown in Table 4.

Table 4 the TDC use showed a significant decrease in period B, 31.895 to $17.38 \%$. These are of course welcoming news.

Table 4. Procedures performed in the Access center

\begin{tabular}{|c|c|c|c|c|c|c|c|c|}
\hline \multicolumn{5}{|l|}{ Pre-follow up program } & \multicolumn{4}{|c|}{ Post-follow up program } \\
\hline Procedure performed & 2006 & 2007 & 2008 & 2009 & 2011 & 2012 & 2013 & 2014 \\
\hline Angioplasty & $39.44 \%$ & $40.27 \%$ & $39.13 \%$ & $40.58 \%$ & $51.04 \%$ & $53.19 \%$ & $50.32 \%$ & $50.46 \%$ \\
\hline angiogram & $8.56 \%$ & $8.26 \%$ & $9.42 \%$ & $9.82 \%$ & $14.76 \%$ & $14.51 \%$ & $16.19 \%$ & $16.80 \%$ \\
\hline $\begin{array}{l}\text { Dialysis access } \\
\text { Thrombectomy }\end{array}$ & $7.25 \%$ & $7.58 \%$ & $6.51 \%$ & $7.97 \%$ & $1.64 \%$ & $1.55 \%$ & $2.68 \%$ & $2.48 \%$ \\
\hline $\begin{array}{l}\text { Hemodialysis catheter } \\
\text { exchange }\end{array}$ & $13.61 \%$ & $9.84 \%$ & $12.5 \%$ & $10.27 \%$ & $6.94 \%$ & $4.81 \%$ & $3.40 \%$ & $3.29 \%$ \\
\hline
\end{tabular}




\begin{tabular}{lllllllll}
\hline Pre-follow up program & & & \multicolumn{5}{c}{ Post-follow up program } \\
\hline Procedure performed & $\mathbf{2 0 0 6}$ & $\mathbf{2 0 0 7}$ & $\mathbf{2 0 0 8}$ & $\mathbf{2 0 0 9}$ & $\mathbf{2 0 1 1}$ & $\mathbf{2 0 1 2}$ & $\mathbf{2 0 1 3}$ & $\mathbf{2 0 1 4}$ \\
\hline $\begin{array}{l}\text { Hemodialysis catheter } \\
\text { removal }\end{array}$ & $7.12 \%$ & $9.50 \%$ & $8.74 \%$ & $10.29 \%$ & $9.93 \%$ & $8.05 \%$ & $6.68 \%$ & $8.43 \%$ \\
$\begin{array}{l}\text { Hemodialysis catheter } \\
\text { placement }\end{array}$ & $5.47 \%$ & $5.54 \%$ & $4.02 \%$ & $2.29 \%$ & $1.72 \%$ & $0.97 \%$ & $1.44 \%$ & $0.62 \%$ \\
$\begin{array}{l}\text { Office visit } \\
\text { Ultrasound }\end{array}$ & $1.78 \%$ & $2.6 \%$ & $2.14 \%$ & $5.08 \%$ & $7.02 \%$ & $6.37 \%$ & $5.96 \%$ & $11.10 \%$ \\
\hline
\end{tabular}

\section{Discussion}

The concept of prospective monitoring with elective intervention to maintain patency of $\mathrm{AV}$ access has been carried out in multiple clinical studies (Schwab, 1999; Besarab, 1995; Kanterman, 1995; Vaiji, 1991; Safa, 1995; Sands, 1995; Turmel-Rodrigues, 1993; Besarab, 1998). This study confirms previous data that preemptive angioplasty of the $\mathrm{AV}$ access has benefits on decreasing the incidence of thrombectomies, access failure and missed dialysis sessions (Schwab, 1995; Besarab, 1995; Safa, 1995).

Different methods for access monitoring are used in our ESRD population (transonic, static \& venous pressure along with blood flow monitoring, and Vasc-alert), but the utility of this methods differ in the different dialysis centers. Owing to multiple logistic factors it is not possible to rely on busy dialysis staff to monitor the accesses and refer patients in timely manner to the access center for PTA intervention, thrombosis prevention, and access maintenance. These constraints prompted us to implement a follow up program to these patients in the dialysis access center. Starting in October 2010, all patients on HD are followed up prospectively on different intervals according to the nature of their underlying lesion on initial angiograms. Their AV accesses are examined by experience interventionalists with ultrasound evaluation and PTA if deemed necessary. The follow up evaluation of the accesses are performed in the access center and the intervals ranging from one to twelve months.

Our results are clearly showed decreased thrombosis rate overall in AVF and AVG following the implementation of the program. This study confirms the previous findings of other workers (Schwab, 1989; Smits, 2001). The reason for this remarkable improvement is not entirely clear. We speculated that close follow up of these patients with attentions to preemptive PTA have significantly decreased the rate of access thrombosis and may have improved the number of patients who are TDC dependent. It is clear that angioplasty rate have increased in the same period. This may be an acceptable trade off to maintain access functionality and patency.

The take home massage is the value of close follow up, monitoring, and prospective PTA in AV access management. Not only does it appear that thromboses are avoided, but the use of TDC have significantly decreased, thereby, preventing the attended complications, e.g. blood stream infection and central vein stenosis.

The appropriate criticism of this program is that monitoring of $\mathrm{AV}$ access to prevent thrombosis merely replaces one intervention with another. The numbers of PTA interventions have doubled (average of (413/year to 801/year, $39.85 \%$ to $51.25 \%$ ) to maintain patency of the AV access. Nonetheless, the use of an elective intervention appears to extend access patency and diminish the need for urgent thrombectomies. The increased incidence of referral because of increased bleeding may reflect the awareness of the dialysis staff to send patients promptly for angiograms. Can these results translate into positive gains? The impact on access longevity and expenditure are not clearly known at this time.

The limitations of this study are that it was carried out in one center and may not be applied in other facilities. The follow up periods is also limited. In addition, a concurrent control group is not used. However, the results of low thrombectomies and decrease rate of TDC use are striking. Replications of this study in multiple centers would increase the authenticity and gives larger confirmatory results to the robustness of the study.

In summary, close follow up of HD patients with preemptive PTA to the AV access prevents thrombosis; maintain access patency, and decrease the missed dialysis sessions. The issue of increase longevity and functionality of these vital conduits are not settled at this time. Active follow up of these patients with pre-emptive angioplasty measures are worthy of further investigations. The ideal long-term therapy in the treatment of AV access is the prevention of fibromuscular and intimal hyperplasia rather than correction of an existing pathological process. This aim remains an aspiration for future endeavor.

\section{Conflict of Interest}

The authors declare that there is no conflict of interests regarding the publication of this paper. 


\section{References}

Allon, M. (2007). "Do we really need periodic monitoring of vascular access for hemodialysis" Nephrology self-assessment program, 6, 111-116.

Besarab, A., Frinak, S., Sherman, R. A., et al. (1998). Simplified measurement of intra-access pressure. J Am Soc Nephrol, 9, 284-289.

Besarab, A., Sullivan, K. I., Ross, R. P., et al. (1995). Utility of intra-access pressure monitoring in detecting and correcting venous outlet stenoses prior to thrombosis. Kidney Int, 47, 1364-1373. http://dx.doi.org/10.1038 /ki.1995.192

Besarab, A., Sullivan, K. L., Ross, R. P., et al. (1995). Utility of intra-access pressure monitoring in detecting and correcting venous outlet stenoses prior to thrombosis. Kidney Int, 47, 1346-1337. http://dx.doi.org/10.1038/ ki.1995.192

Dember, L. M., Holmberg, E. F., Kaufman, J. S., et al. (2004). Randomized controlled trial of prophylactic repair of hemodialysis arteriovenous graft stenosis. Kidney Int, 66, 390-398. http://dx.doi.org/10.1111/j.15231755.2004.00743.x

Feldman, H. I., Kobrin, S., \& Wasserstein, A. (1996). Hemodialysis vascular access morbidity. J Am Soc Nephrol, 7, 523-535.

Gorodetskaya, I., Zenios, S., Mc Culloch, C. E., et al. (2005). Health-related quality of life and estimates of utility in chronic kidney disease. Kidney Int, 68, 2801-2808. http://dx.doi.org/10.1111/j.1523-1755.2005. 00752.x

Kanterman, R. Y., Vesely, T. M., Pilgram, T. K., et al. (1995). Dialysis access grafts: Anatomic location of venous stenosis and results of angioplasty. Radiology, 195, 135-139. http://dx.doi.org/10.1148/radiology.195.1. 7892454

Manns, B., Tonelli, M., Yilmaz, S., et al. (2005). Establishment and maintenance of vascular access in incident hemodialysis patients: A prospective cost analysis. J Am Soc Nephrol, 16, 201-209. http://dx.doi.org/10. 1681/ASN.2004050355

Moist, L. M., Churchill, D. N., House, A. A., et al. (2003). Regular monitoring of access flow compared with monitoring of venous pressure fails to improves graft survival. J AM Soc Nephrol, 14, 2645-2653. http://dx.doi.org/10.1097/01.ASN.0000089562.98338.60

National Kidney Foundation: K/DOQI clinical practice guide-lines for vascular access. (2001). Am J Kidney Dis 37(suppl 1), S137-S181. http://dx.doi.org/10.1016/S0272-6386(01)70007-8

Ram, S. J., Work, J., Caldito, G. C., et al. (2003). A randomized controlled trial of blood flow surveillance of hemodialysis graft. Kidney Int, 64, 272-280. http://dx.doi.org/10.1046/j.1523-1755.2003.00070.x

Safa, A. A., Vaiji, K., Roberts, A. C., et al. (1996). Detection and treatment of dysfunctional hemodialysis access grafts: Effects of surveillance program on graft patency and the incidence of thrombosis. Radiology, 199, 653-657. http://dx.doi.org/10.1148/radiology.199.3.8637982

Sands, J. J., \& Miranda, C. L. (1995). Prolongation of hemodialysis access survival with elective revision. Clin Nephrol, 44, 329-333.

Schwab, S. I., Raymond, J. R., Saeed, M., et al. (1995). Prevention of hemodialysis fistula thrombosis: Early detection of venous stenosis. Kidney Int, 36, 707-1373. http://dx.doi.org/10.1038/ki.1989.250

Schwab, S. J., Harrington, J. T., Singh, A., et al. (1999). Vascular access for hemodialysis. Kidney Int, 55, 2078-2090. http://dx.doi.org/10.1046/j.1523-1755.1999.00409.x

Smits, J. H. M., van der Linden, J., Hagen, E. C., et al. (2001). Graft surveillance: Venous pressure, access flow, or the combination? Kidney Int, 59, 1551-1558. http://dx.doi.org/10.1046/j.1523-1755.2001.0590041551.x

Tessitor, N., Bedogna, V., Poli, A., et al. (2008). Adding access blood flow surveillance to clinical monitoring reduces thrombosis rates and costs, and improves fistula patency in short term: A controlled cohort study. Nephol Dial Transplant, 23, 3578-3584. http://dx.doi.org/10.1093/ndt/gfn275

Turmel-Rodrigues, L., Pengloan, J., Blanchier, D., et al. (1993). Insufficient dialysis shunts: Improved long-term patency rates with close hemodynamic monitoring, repeated Percutaneous balloon angioplasty and stent placement. Radiology, 187, 273-278. http://dx.doi.org/10.1148/radiology.187.1.8451428

U.S. Census Bureau: Statistical Abstract of the United States. (2012). Suitland, MD: U.S Cencsus Bureau. 
USRDS: Annual Data Report: Atlas of Chronic Kidney Disease and End Stage renal Disease in the United States. United States Renal Data System, Bethesda, MD, National Institute of Health, National Institute of Diabetes and Digestive and Kidney Diseases. (2013).

Vaiji, K., Bookstein, J. J., Roberts, A. C., et al. (1991). Pharmacomecanical thrombolysis and angioplasty in the management of clotted hemodialysis grafts: Early and late clinical results. Radiology, 178, 243-247. http://dx.doi.org/10.1148/radiology.178.1.1824582

Whittier, W. L. (2011). Should arteriovenous access flow undergo regular surveillance? Seminars in Dialysis, 24, 389-390. http://dx.doi.org/10.1111/j.1525-139X.2011.00926.x

\section{Copyrights}

Copyright for this article is retained by the author(s), with first publication rights granted to the journal.

This is an open-access article distributed under the terms and conditions of the Creative Commons Attribution license (http://creativecommons.org/licenses/by/3.0/). 